\title{
The enterprise employee management strategy in the Internet transformation
}

\author{
Jingyan Liu \\ International Business School, Jinan University, Zhuhai, 519070, China \\ silentrock@163.com
}

Keywords: Internet Transformation; Employee alternation; Employer Value Proposition

\begin{abstract}
Internet transformation is challenging human resource management in the enterprise, this paper discusses the impact on enterprise employee management of Internet transformation, analyzes the employee management problems in employee supply and demand, knowledge structure and enterprise culture in the alternation between new and old employees, puts forward the employee management strategy based on the employer value proposition and the relevant measures.
\end{abstract}

\section{Introduction}

With the progress of globalization and supply-side reform under the new economic normal, the concept of "Internet plus" has become a hot point in the transformation and upgrading of Chinese enterprises. Through Internet transformation, Internet and traditional industries will be cross-borderly integrated to promote the transformation and upgrading of Chinese industries, to create a new economic ecosystem and enhance the traditional enterprise's innovation capability and competitive advantage. In the process of Internet transformation, Chinese enterprises have to make the corresponding transformation in human resources management [1] [2], both from the external environment and from the pressure within the new and old employees inside the enterprises[3][4]. This paper analyzes the impact on the employee management of Internet transformation, discusses the alternate problems between new and old employees in the process of Internet transformation, and puts forward the employee management strategy based on employer value proposition, to provide the reference for the transformation and upgrading of Chinese enterprises.

\section{Alternation between new and old employees in Internet transformation}

With the continuous deepening promotion of innovation-driven development strategy, Internet and traditional industries are accelerating the integration and promote the rapid growth of new industries and new formats. Through Internet transformation, the application of information technology changes the enterprise operation and business process to promote production management and marketing reform, transform and upgrade the management model and the management thinking, and reshape the industry chain and value chain. Strategic transformation is talent-based. The key issue of innovation-driven is to increase the number and quality of employees and optimize the talent structure. Internet transformation requires the corresponding transformation of human resource management. A profound understanding of the impact on the enterprise employee management of Internet transformation is necessary for enterprise managers [5] [6].

In view of the requirement for industrial upgrading and employees knowledge structure, alternation between new and old employees has become the fundamental part of the human resources management [7][8]. In Internet transformation, industrial upgrading need to make the new economic growth points. The former employees, who have worked in the same industry for a long time, will inevitably form a norm in strategic thinking and management perspective, which result in some limitations on the transformation strategy and the shortage of transformation power, so as to miss the transformation opportunity. The quality and professional skills of the previous employees have been no longer meet the need for the transformation and development of enterprises, showing the three limitations of "invisible", "inflexible" and "out of reach". The new employee can 
objectively survey and plan the enterprise transformation from the perspective of an outsider, and possess the relevant knowledge、skills and experience to promote transformation. Therefore, the alternation between new and old employees represents the general trend. But the alternation should be the integration of new and old culture and ensure cultural heritage, rather than a simple replacement. It is necessary to enhance the value of old employees and avoid their limitations, but also demonstrate the capability and advantages of new employees.

However, there are many problems in the alternation process of employees, which are mainly manifested in the three aspects of employee supply and demand, knowledge structure and corporate culture. First of all, enterprises may deliberately relocate the interests and development of new employees in the restructuring of Internet transformation and impair the interests of the old employees, which led directly to conflicts between new and old employees' attitudes and behaviors, resulting in the turnover of the old employees. In the recruitment process, the corporate image, recruitment channels, remuneration and welfare are less attractive to obtain the new talent, and then the talent gap between supply and demand appears. Secondly, the senior managers and the employees in relevant functional departments need to possess the Internet transformation skills and experience. Most of these employees do not fully possess professional capabilities, and the knowledge structure of the existing talent is deficient. Finally, Internet transformation may separate corporate culture heritage. Internet transformation strategy failed to fully communicate to the employees, so as to lack a consistent vision. The past advantages, outstanding culture and values are ignored or even lost; the new and old employees have different opinions on the future development direction, and corporate identity decline, unable to integrate resources. The cultural conflict and integration caused by the differences in working styles and concepts between the new and old employees place higher requirements for the construction of enterprise culture.

\section{Employee management based on employer value proposition}

The concept of employer value proposition comes from the employer brand. Ambler and Barrow defined the employer brand as a comprehensive concept that is embodied in the employment behaviors as a combination of functional, economic and psychological interests with the employer [9]. In essence, employer brand is in the expression of a value proposition that promotes a people-oriented management philosophy, and manages the enterprise's existing internal and external potential employees. Employer value proposition is concerned about the employment relationship and employee experience, taking employees at the core of enterprise management, and enabling employees to work and grow better in the enterprise.

Through effective communication of employer value proposition inside and outside the enterprise, it is possible to create a distinct employer brand, integrate human resource management activities, and carry out continuous interactive communication with employees. In the process of Internet transformation, enterprises need to manage their human resources based on the employer value proposition, upgrade the capability of strategic transformation, establish continuous interaction with the employees, ensure the acquisition and retention of the transformation talents, and make a contribution for the enterprise transformation [10].

\subsection{The role of employer value proposition}

The construction of employer value proposition can increase organizational value, improve the quality of employees, and enable enterprises to gain a dominant position in the talents competition. At first, employer value propositions can help absorb and retain human resources. A clear employer value proposition can be attractive enough to external potential employees. Through employer value proposition, enterprises provide employees with a satisfactory workplace and working environment, which can gain a higher reputation and appeal in the labor market, attract enough applicants, make it easier to obtain the ideal human resources and reduce the risk of talent supply and demand.

Secondly, through employer value proposition, enterprises can help human resources development, provide specific employment experience for employees, improve the existing 
employee engagement and loyalty, and effectively retain and motivate employees to work better. The employer value proposition emphasizes the value co-creation of enterprises and employees. Instead of simply controlling and restraining employee behaviors, enterprises provide training, education and support for employees to promote their continuous improvement and development. Employees enjoy the work pleasure, and staff structure has high stability, effectively improving work efficiency and service quality. Stable and competent workforce can create the better business performance, not only create value for the enterprise, but also bring value to the external job seekers and internal employees, which achieves the effective identification of the enterprise, and realize the employee self-improvement [11].

\subsection{Communication of employer value proposition}

When communicating value propositions with employees, enterprises should pay attention to employee perception and experience, and use more diversified and effective communication methods to enable employer value proposition and corporate culture to be finally implemented. Employer value propositions should be clear and easily perceived so that they can be disseminated quickly and effectively, attractive for external potential and internal employees .Value proposition should fully meet the needs of employees, ensure authentic and credible through policy system, and realize long-term and continuous interaction with employees. In the construction of employer value proposition system, enterprises should regard employees as the core, reflect the value from the four aspects of work content, work environment, management behavior and organizational characteristics, and select and extract value proposition based on employee demand [12].

The employer should request clear value proposition for employees, to ensure the smooth progress of the work and improve the work performance; then make the appropriate returns for employees to provide employees with attractive employment experience; and ensure the return commitment through the human resources management policies and systems to reflect the corporate concern for employees and the recognition of employee contributions.

In the process of communication, employer value proposition should reflect its own characteristics, and realize the differentiation of talent competition with competitors, which highlights the core advantages of enterprises. Employer value proposition should match the organizational form of the enterprise, and the value proposition should be chosen according to the type of enterprises. There are three main types of employer value propositions. The first type emphasizes on enterprise stability and the status in the industry, and the strength in the internationalization, enterprise scale and industry reputation, mostly in large multinational corporations. The second emphasizes the specific employment experience, focusing on the challenge of work and self-fulfilling of employees, mostly in emerging industries and growth-oriented enterprises. The third gives priority to social recognition, focusing on the successful people in the business and professional fields, mostly in the initial stage of entrepreneurial enterprises and small and medium-sized enterprises.

Traditional employer brands are enterprise-centered, one-way communication from top to bottom, and cannot fully obtain employees' approval. Human resource management based on the employer value proposition is employee-centered, pays great attention to employees' work experience and encourages employees to put forward personal opinions and value demands. Enterprises combines employer value proposition with employees' values through the corresponding management activities, achieve positive interaction and two-ways communication, closely link employee and enterprise to improve the competitive advantage of [13].

\section{Implementation of enterprise employee management in Internet transformation}

In response to the problems arising from the alternation between new and old employees in Internet transformation, employee management activities based on the employer value proposition can be embodied in the following aspects. 


\subsection{Acquisition and retention}

What needs to be done on the issue of employee supply and demand is the acquisition and retention of qualified personnel. The main factors that enterprises should consider to attract external talents based on employer value proposition, such as compensation and benefits, development opportunities, working environment and corporate reputation, are all important components of employer's value proposition. The talent recruitment strategy is formulated to emphasize own advantage according to the required target talent [14].

Enterprises can also attract the followup talents by publicizing the halo effect and social identity of the leaders of the industry. Xiaomi invited famous expert Zhou Guangping as a co-founder in the start-up period. His powerful influence in the professional field makes it possible to recruit more than a dozen senior engineers in the short term and quickly formed a hardware team.

In addition to formulating talent retention plans through regular performance, employees can be provided with better working conditions and greater development space through organizational change and innovation, thereby reducing employee turnover rate [15]. GE's slogan "Sharing a Belief, Making it Real” implements its employer value proposition “GE \& ME” and encourages employees to share work experience and professional experience so that employees have a strong emotional connection to GE, and establish long-term commitment [16]. Tencent empowers employees through corporate business restructuring in order to meet the diversified development demands of employees and effectively retain qualified personnel.

\subsection{Human resource development of employees}

Human resource development may solve the shortage problem of employee's knowledge structure. Internet transformation requires the upgrading of specialized knowledge and skills. Employees should have the awareness of self-learning, and continuous improvement, and constantly strengthen self-monitoring and self-management capabilities [17].

\subsection{Enterprise culture construction}

Internet transformation has increased the cross-border flow of talents, bringing the cultural conflict and integration of new and old enterprises employees. Based on the long-term corporate vision and transformation strategy, the core elements of enterprise culture are defined, the needs of employees are integrated, the value proposition is identified and embodied in the business process and the incentive mechanism, which promotes the interaction of new and old employees and accelerates cultural integration with continuous cultural heritage.

\subsection{Attractiveness to the new generation of employees}

The new generation of employees, the main force of enterprise transformation and development, is accustomed to information communication and dissemination through the Internet and open systems, self-centered and more flexible in work, emphasizing personal development goals and values while weakening the authority and power constraints. Therefore, enterprises should provide a relatively independent and comfortable working environment, use a wide range of recruitment channels, advocate an innovative and passionate organizational culture, increase the interaction through social media, event recruitment and public welfare competitions and other ways, reflecting the attractive corporate image and value proposition.

\section{Conclusions}

Internet development patterns and management models in China have created the Chinese characteristics. Internet transformation has merged local enterprises' transformation and upgrading and the Internet. Human resource management activities need the corresponding innovation. By reshaping employer value proposition, the enterprises reach a consensus on strategic transformation goals, advocating an innovative and integrated organizational culture, to meet the demand of 
Internet transformation, achieve the value creation of human resources and enhance the competitiveness of enterprises.

\section{Acknowledgement}

In this paper, the research was sponsored by the Science and Technology Planning Project of Guangdong Province (Project No. 2014A070703024).

\section{References}

[1] Niu ling.Research on the transformation of human resource management based on Internet thinking [J]. China Management Informationization, 2016, (20):46-47.

[2] Peng Jianfeng.New thinking of human resource management in Internet Era [J].Human resource development of china, 2014, (16):6-9.

[3] Zhu Kexin. Human resources management transformation ideas on "Internet" manufacturing enterprise [J]. Chinese \&foreign entrepreneurs, 2016, (19):167-168.

[4] Meng Liping. The transformation and upgrading of Internet human resources management [J]. Oriental Enterprise Culture, 2015, (17):117.

[5] Fu Tao. The matching effect between human resources development and industrial transformation and upgrading: an analysis with Guangdong as an example [J], Journal of Guangdong University of Finance and Economics, 2016, (03):72-81.

[6] Chen Ni. Industrial transformation and upgrading and human resources development [D], Xiamen University, 2014.

[7] BCG, Chinese Companies journey to a new normal globalization and Internet [EB/OL],2016-05-25,http://www.bcg.com.cn/export/sites/default/cn/files/publications/reports_ pdf/BCG_Chinese_Companiesx_Journey_to_a_New_Normalx_Globalizationx_and_Internetx_ May_2016_CHN.pdf

[8] .Jia RuiXian. The research of human resource management transformation base on the internet thinking--for instance Haier[D],Maritime affairs university of Dalian,2015

[9] Ambler T, Barrow S. The employer brand [J]. Journal of Brand Management, 1996, 4(3): 185206.

[10]Roger E Herman, Joyce L Gioia. Helping your organization become an employer of choice [J]. Employment Relations Today, 2001, (Sum.): 63- 78.

[11] Yin Zhiping. A review of employer brand research [J], Foreign Economics\& Management, 2007, (10):32-38.

[12].Fu Shaohong. The value of employer brand and the construction approach [J]. Market modernization, 2006,(34):254-255

[13]Zhang Wenrong. Construction and value of employer brand [J]. Human resource management, 2013, (07):116-117.

[14]Muzi. Let career choice return to the heart -- "GE\&ME" employer value new proposition [J]. Career, 2012, (31):109.

[15]Xie Yunliang. Research on human resources development under the industrial transformation and upgrading in the Pearl River Delta -- Taking Foshan as an example [J]. Technology and enterprises, 2013, (06):50-51. 
[16] He Weihua,Research on human resources of industrial transformation and upgrading in Pearl River Delta[D], Tibet University, 2010.

[17]Zhu yongyue,Xia zhengjing,Hu guanglan,etc.Human resources management models of manufacturing companies under the service transformation background[J],Forum on science and technology in China,2016,(05):136-141. 